\title{
Transformed Perspective: Building an understanding of culture and the conditions of women through their lens.
}

\section{Perspectiva Transformada: Entendiendo la cultura y las condiciones de mujeres a través de su propio lente.}

\section{HEATHER A. RULE}

Architect, Austin, Texas, USA

heather.a.rule@gmail.com

\section{RESUMEN}

Una de las misiones de Fulbright es el intercambio cultural. Entender y ser entendido mediante el intercambio de experiencias y conocimiento es esencial para tener empatía entre naciones y personas. El ensayo que sigue es una reflexión del impacto y los aprendizajes de una becaria de investigación del programa Fulbright US Student durante la estancia en Ecuador entre 2016-2017. El trabajar con mujeres en fincas florícolas ecuatorianas, contribuyó al entendimiento del ambiente construido y las condiciones de las mujeres. Los aprendizajes y el impacto personal de la experiencia de Fulbright fue mucho más allá que el proyecto de investigación.

Palabras Clave:

Intercambio cultural, experiencia Fulbright, mujeres, feminismo, industria florícola

\section{ABSTRACT}

Cultural exchange is the basis of the Fulbright mission. To understand and be understood through the exchange of experiences and knowledge is essential to creating empathy between nations and people. The following is a reflection on the impact and lessons of a Fulbright US Student research grantee during her time in Ecuador in 2016-2017. Her research with women working on flower farms in the highlands of Ecuador led her to new understandings of the built environment and conditions of women. The lessons learned and the personal impact of the Fulbright experience went beyond that of a research project.

Key Words:

cultural exchange, Fulbright experience, women, feminism, flower industry. 


\section{INTRODUCTION}

"Your project will change" I was told the first day I checked in at the Fulbright Commission in Quito, Ecuador. My immediate reaction was resistance, after all, was it not my research proposal that got me accepted? I had submitted a proposal that had considered all the factors, or so I thought. Over the course of the next ten months I would realize just how true that initial statement was and would appreciate being prepared for the inevitable adjustments to my research process. This lesson was valuable, both in the flexibility with which I learned to pursue my research and in how I kept an open mind as I worked with the women that participated in the research. It prepared me to learn about the Ecuadorian culture and customs with an unrestricted perspective. These are the types of lessons we gain from a cultural exchange that make programs like Fulbright essential to creating empathy and understanding between cultures and people.

\section{Choosing Women in the Flower Industry}

My research proposed studying the agency of women in the rural built environment of Ecuador. Working specifically with women in the flower industry, I wanted to understand how the economic impact of receiving salaries for their employment at flower farms had an influence and/or

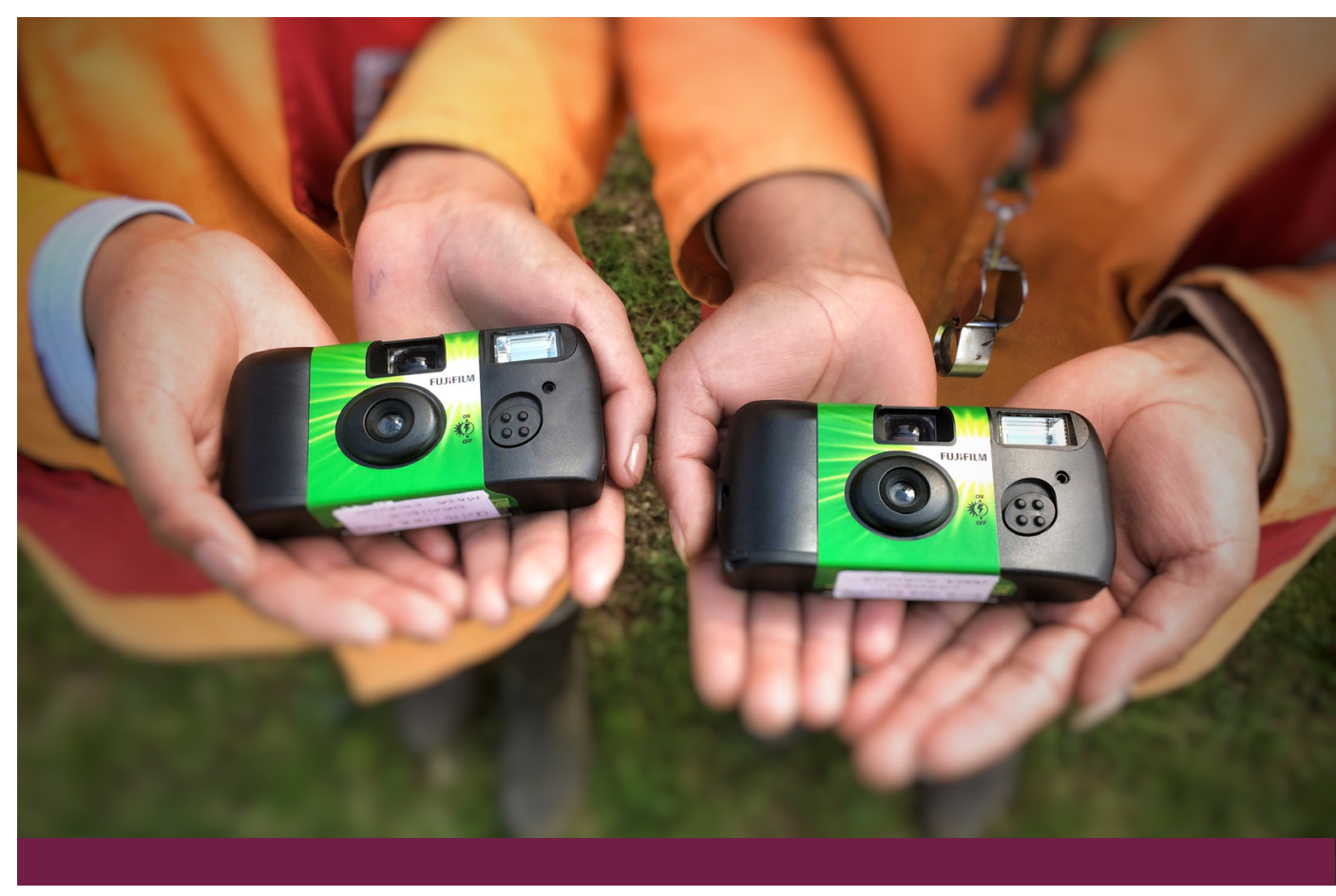

Image 1. Disposable cameras used by women to document their built environments. Photo taken by Heather Rule. 2017. 
effect on the homes and communities they lived in. The flower industry in Ecuador has impacted the agrarian land use and the livelihoods of women in the Cayambe region since its growth began in the 1980's (Becker, 2009). According to the statistics kept by Expoflores, the National Association of Producers and Exporters of Flowers of Ecuador, women currently represent $51 \%$ of the workers in the industry. Being an industry that is mainly located in rural areas this has a direct impact on the livelihoods of women.

As an architect, I am interested in how people affect the built environment they live and work in and in turn how that built environment effects

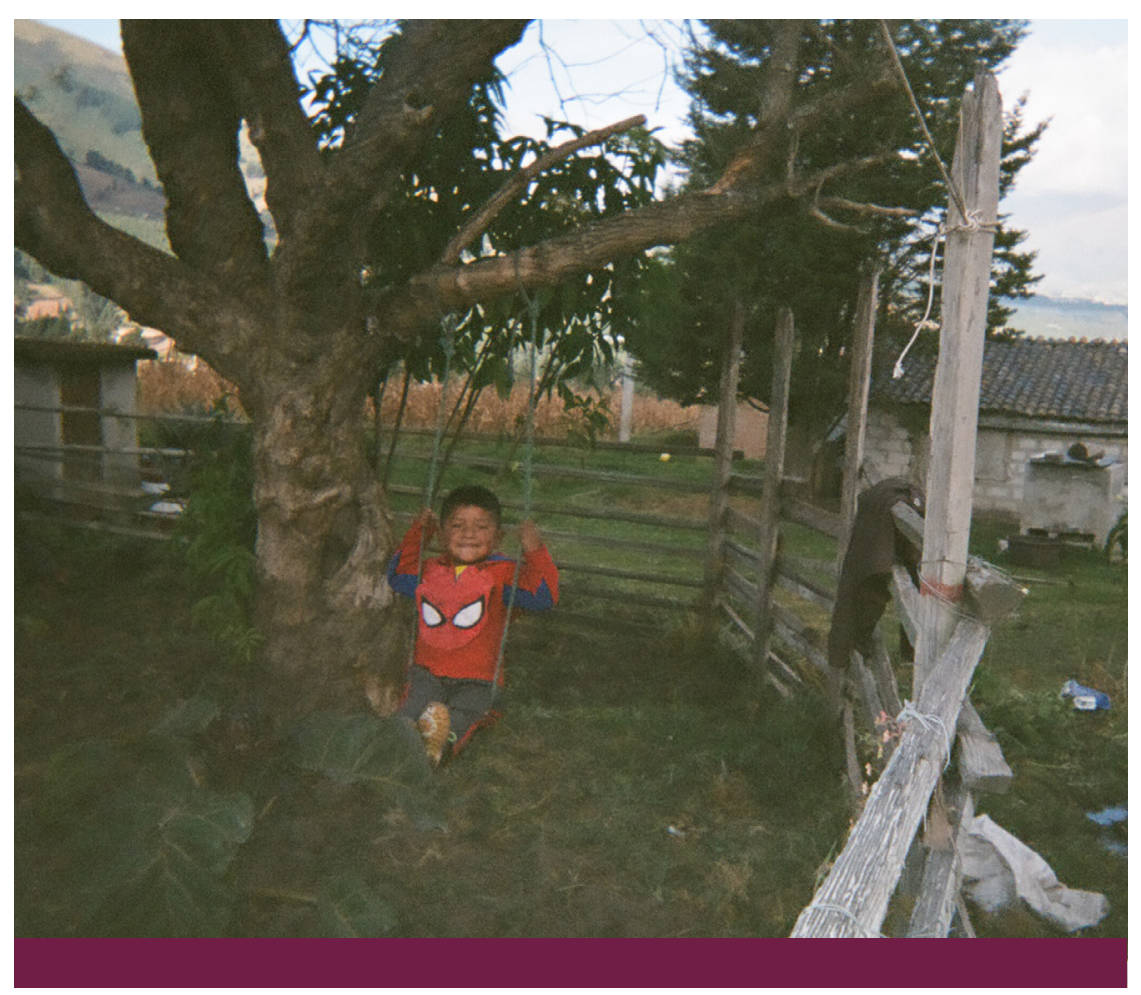

them. For this research, the built environment can be defined as any physical place that is used or manipulated by people. As a woman and feminist, I am specifically interested in these topics from a gendered perspective.

In my grant application I proposed using participatory design methods to map women's lives in their homes, communities and work places. One of the lessons I had to learn early on was that the first step to a research project with human subjects is building relationships. My proposed methods and approach needed to be reevaluated. I started collaborating with people in the flower industry to build an understanding of the history and present state of challenges within the industry. This process allowed me to build relationships and opened my eyes to perspectives I had not previously considered.

Recognizing that the perspective of others is more valuable than my interpretation of their lives, I adjusted my research methods. Using disposable cameras and a list of provocations I worked with twenty women on four rose farms to document their homes, communities and work spaces. These adjustments did not mean I had to drop my pursuit of understanding the agency of women in the built environment. Instead I had to change the methods I used to research and document these interests in a way that was responsive to the culture I was living in and the women I was working with.

\section{Seeing through a different lens}

In the past, the flower industry in Ecuador battled issues of child labor. As a result, campaigns and programs were implemented to raise

Image 2. Young boy on homemade swing in the chakra. Photo taken by Maria Celia Llenera Cuascota. 2017 


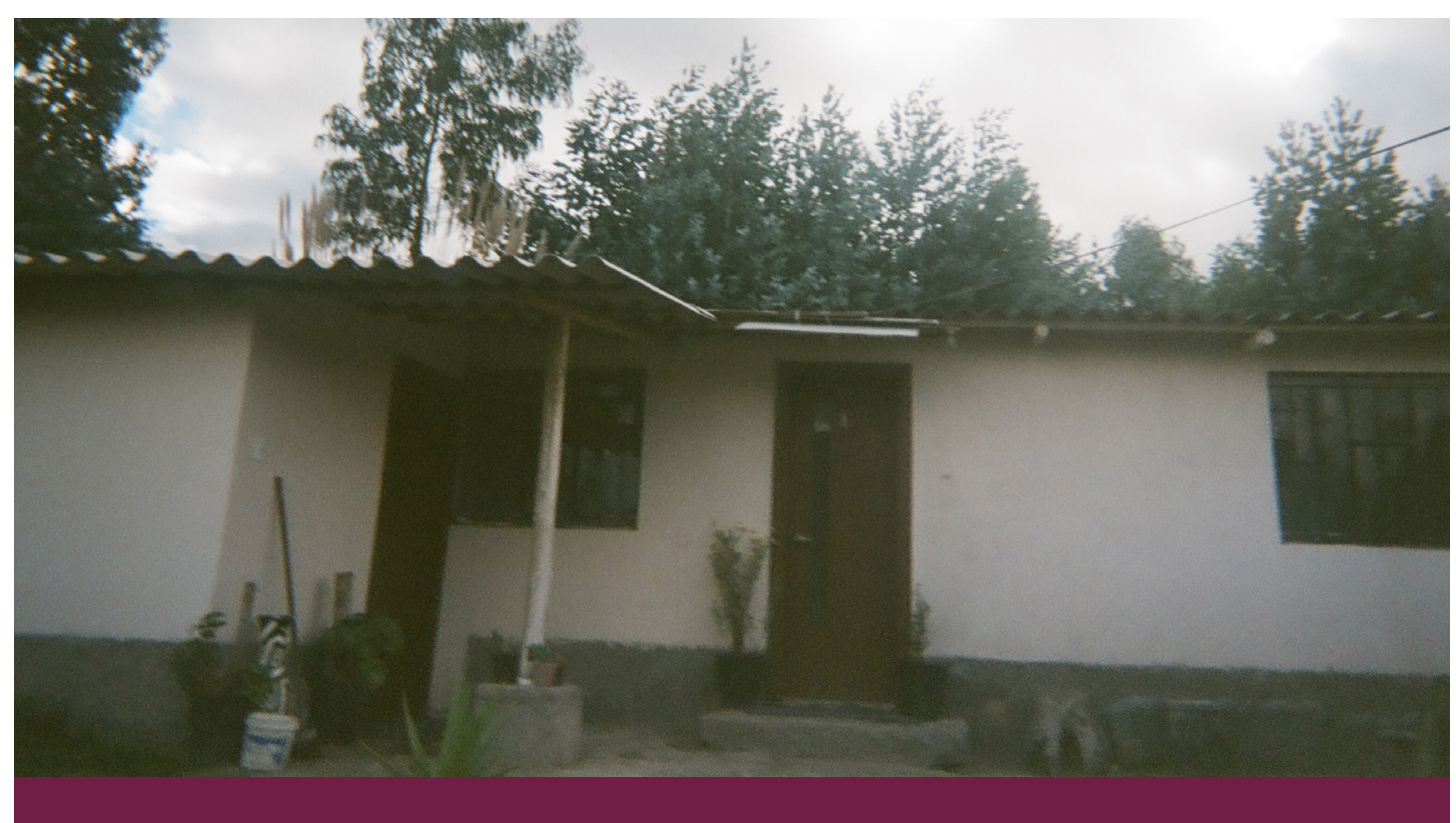

Image 3. "The house I built." Photo taken by Susana. 2017

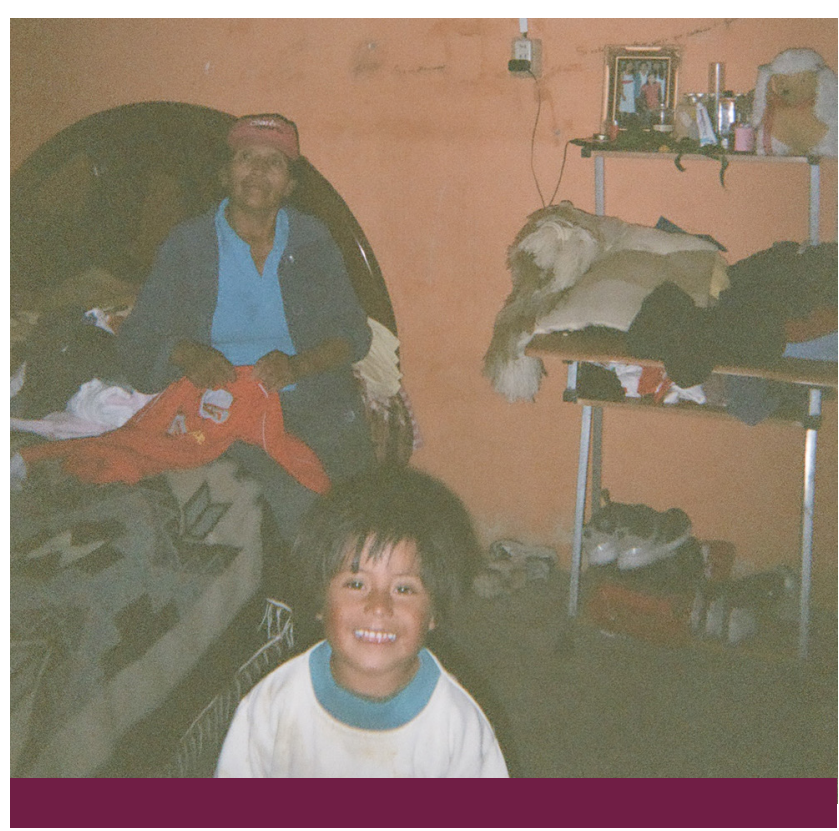

Image 4. "A home for my children." Photo taken by Liliana awareness and end child labor within the industry. My collaboration with the area of social responsibility at Expoflores opened my eyes to the impact the projects they executed over the last several years could have on the lives of families, especially women and their relationship with their children. Through the projects they carried out they went beyond just ending child labor and into developing an understanding from both the employers and employees that children must remain in school and there were other alternatives for economic development for families. These changes are evident in the ways in which the mothers that work on flower farms speak of the importance of keeping their children in school as a way to build a better future for them.
Their built environments also show evidence of the impact these programs have had on families. Maria Celia, one of the women who participated in the camera project, shows this impact in the photo she took of her son enjoying the homemade swing installed on a tree in their chakra (the family garden). In a small, yet significant way, this photo is the visual representation of these processes that have eliminated child labor and empowered women. This image touched my heart. A swing is one of those life pleasures I enjoy and that takes me back to memories of my own childhood. Feelings of freedom and joy are captured in the ungrounded motion of swinging. This photo reminded me that we share as many similarities as we have differences between people and cultures. 


\section{Changing my Perspective}

Two writings I was exposed to during my graduate studies had an influence on how I question and think of the conditions of women and the built environment. In her research about kitchen spaces, Maria Elisa Christie (2006), questioned the typical feminist dialogue of kitchens as spaces of oppression of women and argued that women in central Mexico found these to be spaces of empowerment. Friedman (1992) presents the case for the role culture plays in gender and in understanding gender roles. History and research about women generally shows us that women are more likely to invest their money in ways that benefits their children and family. I was interested in further understanding how this related to their investment in the built environment. Did they build or change their homes as a result of having an income? Did they become more involved in the development of spaces in their communities? While these questions are the basis of research I hope to share in another forum, it was the lessons I learned from how these women, directly and indirectly, answered them that had a profound impact on changing my perspective.

Having employment on rose farms, where they are receiving their own money allows them to build savings and to access credit on their own. They use their income to build a better future for their children. This is consistent with what we know about how women spend money. What I learned from these women is that it is not enough to just provide education and a house for your children. Their economic independence has allowed women in abusive relationships to leave their partners because they are no longer dependent on them to provide a home for their children. For many of them, a reason for leaving violent partners was to create a safe place for their children. They have realized that raising children in a non-violent environment is vital to breaking the cycles of gender violence.

\section{CONCLUSION}

In the end my project changed, but more pointedly I changed. I return to the United States with a transformed perspective. The women I worked with and the people that became a part of my life in Ecuador gifted me with new questions and outlooks. They became my friends, collaborators and mentors.

I was based in the capital city of Quito, due to my academic and host organizations locations, but I travelled frequently to the more rural areas of Cayambe-Tabacundo and Lasso to work with women on flower farms. This gave me the opportunity to witness both the urban and rural contexts of life for women in Ecuador. Being simultaneously embedded in a range of conditions exposed me to the spectrum within the waves of feminism that are currently present in Ecuador. It made me realize it is a disservice to generalize the present or past context of a culture from a whole country perspective.

The most succinct way to summarize the impact of this cultural exchange can be shared in an anecdote. One of the women I had the honor of collaborating with at Expoflores looked at me one day and said "you are the first person from the United States that I have liked." This was a defining moment because I realized we unfairly judge other cultures based on our limited exposure to the people that represent them. It was that moment where I realized that my research, the reason I supposedly had come to Ecuador, was secondary to the cultural exchange element of Fulbright grants. While I believe that my research can contribute to advancing the conditions of women, I also learned that the personal relationships I built came first and had the greatest impact. 


\section{ACKNOWLEDGEMENTS}

My time in Ecuador was funded by a Fulbright US Student Research grant. The backing received from the Fulbright Commission in Ecuador, especially from Susana Cabeza de Vaca and Karen Aguilar, and the US Embassy in Quito was instrumental. Having my fellow Fulbright grantees as a research sounding board and support system made the grant year a transformative experience.

I am grateful for the advice received from Professor Michael Hill, Ph.D. at the Universidad San Francisco de Quito whose insights were influential to my research. Within the flower industry I received support from Expoflores, Royal Flowers, BellaRosa, and Quito Inor Flowers, the farms that allowed me to connect with the women working in their organizations. Finally, I must thank my family for their support and especially my father Dean Rule for the connections he established within the flower industry that were essential to my research.

\section{REFERENCES}

Becker, Marc y Silvia Tutillo. 2009. Historia Agraria y Social de Cayambe. Quito: FLACSO, Sede Ecuador : Ediciones Abya Yala : 233-241

Friedman, John. 1992. Empowerment: The Politics of Alternative Development. Cambridge: Blackwell : 107-126.

Christie, Maria Elisa. 2006. Kitchenspace: Gendered territory in central Mexico. Gender, Place and Culture 13(6): 653-661

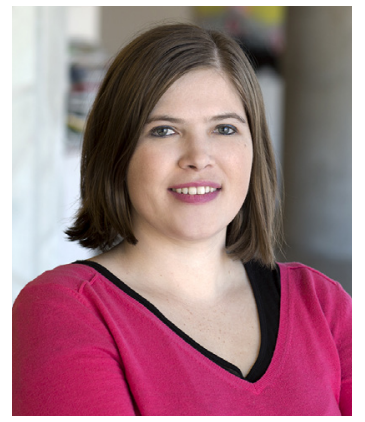

\section{HEATHER A RULE}

heather.a.rule@gmail.com

Heather Rule is a licensed architect who combines research, design and advocacy. She is a passionate advocate of women's rights and equitable environments through research. Her education includes a Bachelor of Science in Architecture from the University of Michigan in Ann Arbor. She received a Master of Architecture from the University of Texas at Austin and was the first student to pursue and receive the Latin American Architecture Certificate. During this time her research began to focus on the conditions of women in the built environment with a focus on South America. Her professional experience encompasses healthcare, institutional and commercial projects around the United States. She received and completed a Fulbright US Student Researcher grant to study the agency of women in the built environment of rural Ecuador. 